\title{
A Dynamic Ice-structure Interaction Model for Prediction of Ice-induced Vibration
}

\author{
Tianyu $\mathrm{Wu}^{1}$, Wenliang Qiu ${ }^{1 *}$ \\ 1 School of Civil Engineering, Dalian University of Technology, \\ No.2 Linggong Road, Dalian City, Liaoning Province, China \\ *Corresponding author, e-mail: qwl@dlut.edu.cn
}

Received: 04 September 2018, Accepted: 12 March 2019, Published online: 15 April 2019

\begin{abstract}
Sea ice crashing against offshore structures can cause strong ice-induced vibration and have a major impact on offshore structural safety and serviceability. This paper describes a numerical method for the prediction of ice-induced vibration when a vertical offshore structure is subjected to the impact of sea ice. In this approach, negative damping theory and fracture length theory are combined and, along with ice strength-stress rate curve and ice failure length, are coupled to model the internal fluctuating nature of ice load. Considering the elastic deformation of ice and the effect of non-simultaneous crushing failure of local contact between ice and structures, the present ice-induced vibration model is established, and the general features of the interaction process are captured. To verify its efficacy, the presented simulation methodology is subjected to a model test and two full-scale measurements based on referenced studies. Example calculations show good agreement with the results of the model test and full-scale measurements, which directly indicates the validity of the proposed simulation method. In addition, the numerical simulation method can be used in connection with FE programs to perform ice-induced vibration analysis of offshore structures.
\end{abstract}

\section{Keywords}

ice load, ice-induced vibration, numerical model, dynamic ice-structure interaction

\section{Introduction}

Ice force is a type of non-negligible external load that nature exerts on structures. The action of drifting ice floes may induce strong vibrations in offshore structures and further reduce their structural safety and serviceability. The interaction between the ice and structure may induce severe vibrations under certain velocities [1]. Level ice acting on a vertically sided offshore structure may induce several kinds of interactions, depending on ice properties and structural properties [2-3].

When a drifting ice floe brushes against an offshore structure, ice crushing failure is the most common failure mode. Different regimes of ice action and ice-structure interaction can be distinguished. The different failure modes of ice are depicted in Fig. 1. Sodhi introduced the concept of ductile crushing, intermittent crushing and brittle crushing, which are mainly controlled by the relative velocity [4]. The borders of the three crushing failure modes are supposed to be separated by transition speeds $v_{1}$ and $v_{2}$, as shown in Fig. 1. Kärnä proposed that the upper transition speed $v_{2}$ depends on structural damping and proposed that the ice-induced steady state vibrations might be mitigated by introducing sufficient structural damping [5]. Hendrikse divided the ice-induced vibration into three distinct regimes of ice-structure interaction [6]. Starting from the lowest ice sheet velocity, these regimes are defined as intermittent crushing, frequency lock-in, and continuous brittle crushing. Frequency lock-in is the most dangerous situation during the interaction between ice and structure and has received the most attention, as it may induce the most severe structure vibrations.

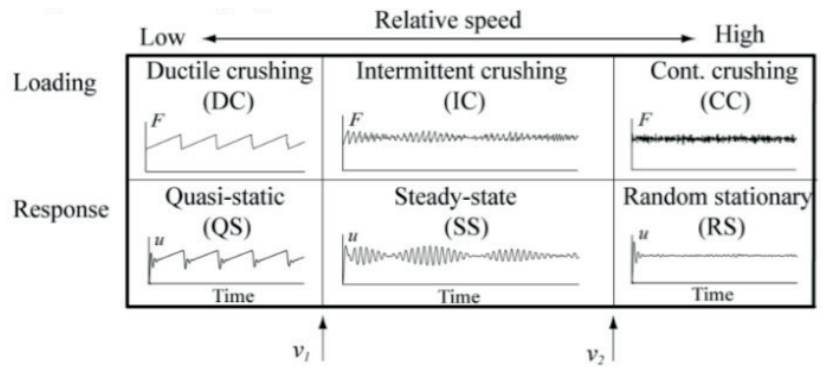

Fig. 1 Types of dynamic ice-structure interactions [13] 
Several theories can explain the occurrence of ice-induced vibration. Currently, two main viewpoints exist for explaining the ice-structure interaction. The first theory is called negative damping, which regards the ice-induced vibration as a result of a negative slope in the dependence of ice strength on ice velocity. Hossain used the negative damping effect to account for ice-structure coupling by using the strength vs. stress rate relationship [7]. Nandan utilized the negative damping theory to predict the onset of ice-induced vibration based on ice crushing properties and structural period [8]. The second theory holds that ice failure is the cause of fracture frequency [9]. When the fracture frequency is close to one of the natural frequencies of the structures, it results in resonance-like behavior. Withalm proposed an extended Matlock-model of ice-structure interaction process in ice-induced vibrations and considered the fracture frequency of ice in the model [10]. Hendrikse developed an ice-induced vibration model that considers the local contact between ice and structures, elastic deformation of ice, and crushing failure frequency [11]. Ji proposed a novel physical mechanism combination between self-excited vibration and forced vibration and considered the coupling effect of ice stress-strain rate curve and ice failure length [12].

Compared to the traditional ice-induced vibration model, the contribution of this paper lies in combining the negative damping theory and crushing failure length of ice, together with ice strength-stress rate curve and ice failure length, to model the internal fluctuating nature of ice force in conjunction with relative velocity. The advantage of the model described in this paper also lies in the consideration of elastic deformation of ice and non-simultaneous crushing failure of local contact between ice and structure. As shown by experimental simulations and the full-scale measurements, the present model can predict ice-induced vibration of offshore structures with varying stiffness.

This paper will first give an overview of the model based on its simulated approach procedure. Subsequently, the results of simulations with varied structure and ice parameters in terms of the referenced studies are presented. The numerical model captures the general features of the interaction process. It has been shown that the presented model is able to reproduce the process of ice-structure interaction for the model experiment and the full-scale structure. In addition, the numerical simulation method can be used in connection with FE programs to perform ice-induced vibrations analysis of offshore structures.

\section{Mechanical properties of ice crushing}

\subsection{Effective ice pressure}

The ice force on a structure depends on the mode in which ice crushing take place. It is convenient to express the ice force in terms of an effective pressure, which is defined as the global ice force divided by the nominal contact area. Assuming that failure due to fracture does not occur, a number of empirical and analytical solutions are available. The ice force exerted on a structure by an ice sheet duo to crushing failure is

$F=p_{e} D h$,

where $F$ is the ice load, $p_{e}$ represents the effective ice pressure, $D$ denotes the contact width, and $h$ denotes the ice thickness.

The effective ice pressure is related to the ice crushing strength by a number of coefficients that each have a physical interpretation. Korzhavin proposed such a relationship, as Fig. (2) [14].

$p_{e}=I f_{c} m\left(v_{i c e} / v_{0}\right)^{-0.333} \sigma_{c}$,

where $I$ represents the indentation coefficient to account for confining effects; $f_{c}$, the contact factor accounting for non-simultaneous contact between the indenter and the ice; $m$ denotes the shape factor; $v_{i c e}$, the velocity of the ice sheet; $v_{0}$, a reference velocity of 1 meter per second; and, $\sigma_{c}$ the crushing strength of the ice.

Therefore, we can express the reduction coefficient as

$q=I f_{c} m\left(v / v_{0}\right)^{-0.333}$.

The global ice force can be expressed as

$F=q D h \sigma_{c}$.

\subsection{Ice crushing strength}

The crushing force and crushing strength are commonly assumed to be functions of loading rate. Timoshenko and Goodier showed that, according to elastic contact theory, the stress varies with the polar angle off the ice drift direction with a cosine distribution [15]. Owing to the variation in stress, the stress rate will also vary over the interaction area. Määttänen gave the following expression for the stress rate [16]:

$\dot{\sigma}=\left(v_{i c e}-\dot{u}\right) \cos ^{2}\left(\theta_{j}\right) \frac{8 \sigma_{c}(\dot{\sigma})}{\pi D}$,

where $v_{\text {ice }}$ is the ice velocity, $\dot{u}$ is the structure velocity, and $D$ is the structure width. 
A special class of models for ice-induced vibration considers the stress rate as an important factor controlling the ice-induced vibration [17]. They suggest that the loading rate during self-excited vibration varies around the transitional zone. Such models assume that the ice adjacent to the structure is always at a failure condition. The decrease in ice strength with increasing stress rate can then be interpreted as a source for negative damping, and this negative damping is proposed to be the origin of a selfexcited vibration.

The maximum crushing strength of ice strongly depends on the stress rate of ice. Määttänen established a stress rate dependent expression for ice crushing strength, and the formula may be approximated by the following nonlinear polynomial [18]:

$$
\begin{aligned}
& \sigma_{c}(\dot{\sigma})\left\{\begin{array}{c}
\lambda\left(2.00+7.80 \dot{\sigma}-18.57 \dot{\sigma}^{2}+13.00 \dot{\sigma}^{3}-2.91 \dot{\sigma}^{4}\right) \\
\lambda
\end{array}\right. \\
& M P a \quad \text { for } \dot{\sigma}<1.3 \mathrm{MPa} / \mathrm{s} \\
& \mathrm{MPa} \text { for } \dot{\sigma} \geq 1.3 \mathrm{MPa} / \mathrm{s}
\end{aligned}
$$

where $\lambda$ is a reduction coefficient of controlling the level of the global ice force, instead of the scaling term $\left(A_{0} / A\right)^{0.5}$. $A_{0}$ is the reference area considering the non-simultaneous failure of ice. $A$ is the contact area of ice and structure interaction. $\dot{\sigma}$ is the ice stress rate. In a transitional zone between ductile and brittle behavior, ice strength decreases with an increasing stress rate.

\subsection{Ice stiffness}

To take into account the ice deformation during contact, a linear model, which has previously been shown to capture the dynamically important behavior [19-20], is considered, even though in principle, ice deformation is a nonlinear process. Ice is therefore taken as an ideal spring. According to Karna and Turunen, the spring stiffness of ice is expressed as Eq. (7) [21]:

$$
K_{e, j}=\left(\frac{1}{E_{e f} f \cdot A_{j}}+\frac{4.58-v}{\pi \cdot E_{\text {ice }} \cdot h}\right)^{-1},
$$

where $A_{j}$ is the contact area and $v$ is the Poisson's ratio of ice (usually taken as $v=0.33$ ). Furthermore, $E_{i c e}$ is the theoretical Young's modulus of ice and $E_{e f f}$ is the so-called effective Young's modulus of ice. The effective modulus amounts to approximately $5 \%$ of the theoretical modulus owing to the formation of small micro cracks under load [21]. Other authors use higher values (up to $50 \%$ ).
Experiments carried out by Timco with flat-faced indenters in freshwater ice have shown that during the crushing mode, there is a region in front of the indenter that contains a high density of microcracks [22]. These microcracks reduce the stiffness of the ice sheet as seen by the structure. Eranti has measured this effect in natural lakes and sea ice plates using circular indenters [23]. His measurements indicated that the stiffness of small ice plates in the penetration phase is given by Eq. (8):

$$
K_{p, j}=\frac{m A_{j}}{\alpha h},
$$

where $m$ is a shape factor, $m=1$, and $\alpha$ is an experimental parameter for which $\alpha=0.003 \mathrm{~m}^{2}(\mathrm{MN})^{-1}$. Due to the test setup, the influence of the virgin ice was negligible in Eranti's test results. Eq. (8) can be alternatively written as Eq. (9):

$K_{p, j}=E_{p} A_{j} / h$,

where $A_{j}=D_{j} h$ and $E_{p}=m / \alpha \approx 300 \mathrm{MPa}$. Hence, the field of microcracks acts as a uniform bar of length $h$ and axial stiffness $E_{p} A_{j}$. This bar represents a spring in series with the elastic ice sheet. The overall stiffness $K_{i c e, j}$ of the ice sheet is therefore given by the expression:

$\frac{1}{K_{i c e, j}}=\frac{1}{K_{e, j}}+\frac{1}{K_{p, j}}$

\subsection{Failure length of ice crushing}

Ice failure length is an idealized concept for numerical calculation based on the damage region or crushing zone. $\mathrm{Ji}$ and Oterkus proposed that ice failure length is taken as a constant $1 / 3$ of ice thickness, which means that ice fails at a certain length if ice thickness does not vary [24]. Sodhi and Morris conducted small-scale tests pushing different diameter rigid cylinders at different velocities against ice sheets with different thickness and found that the ice failure frequency is strongly proportional to ice velocity and slightly inversely proportional to diameter, and they proposed that the ratio of the ice thickness to ice failure length ranges from 2 to 5, with an average value of approximately 3 [25]. The failure length of ice crushing is expected to depend on the ice thickness and ice crushing modes. Small-scale indentation tests show that the crushing length may attain values in the range of $1 / 5$ to $1 / 2$ of the ice thickness [26]. It is evident that these values are relevant in conditions where ice crushing is influenced by additional effects such as spalling and radical cracking. 


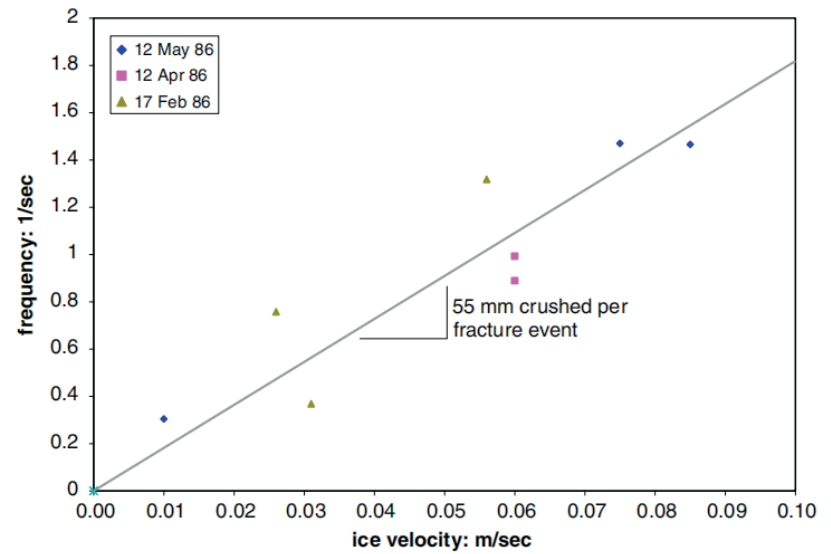

Fig. 2 Failure frequency vs ice velocity for events of ice-Molikpaq [28]

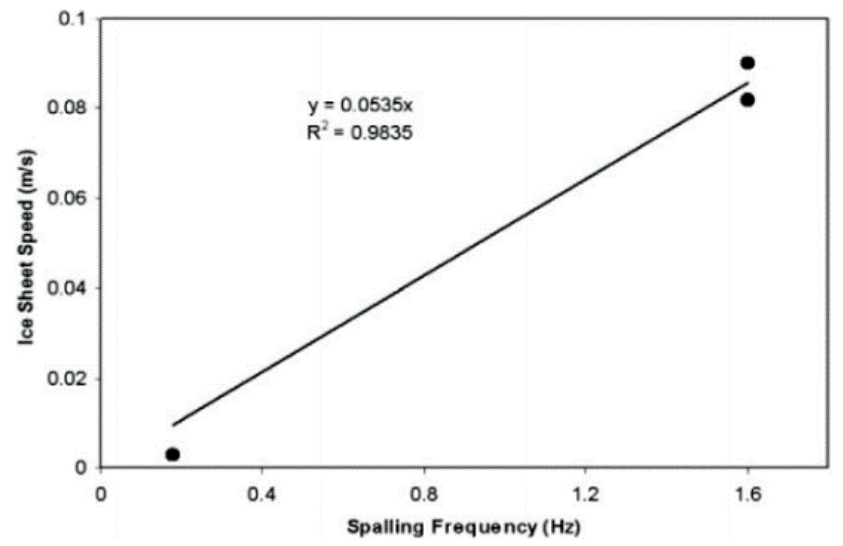

Fig. 3 Ice velocity vs failure frequency for three data points from May 12, 1986 at Molikpaq [29]

However, the full-scale measurements reported by Jefferies indicate that the crushing length is smaller for pure crushing in thick sea ice [27]. Fig. 2 shows the ice fracture frequency versus ice velocity for three separate ice-interaction events at the Molikpaq location. Jefferies determines the failure length of ice crushing to be $5.5 \mathrm{~cm}$ [28]. Fig. 3 shows the ice velocity versus spalling frequency for three data points at the Molikpaq location. Gagnon also determines the similar failure length of ice crushing to be $5.4 \mathrm{~cm}$ and shows that the crushing length may attain values $1 / 50$ of the ice thickness [29]. Accordingly, crushing length is assumed to be $1 / 3$ of the ice thickness in the simulation of the experiment and $1 / 50$ of the ice thickness in the simulation of the full-scales in the present computations.

\section{Numerical analysis model}

\subsection{Dynamic equilibrium equation}

As a representation for the structure, a single degree of freedom oscillator is used. This is the simplest way of representing one mode of vibration of a structure, which is deemed sufficient to model the fundamentals of interaction process. The vibration of the structure is described using the general equation of equilibrium as Eq. (11):

$M \ddot{u}+C \dot{u}+K u=F_{i c e}(t)$,

where $M$ is the mass of the system, $C$ is the damping coefficient, $K$ is the spring stiffness and $F_{i c e}(t)$ is the global ice force acting on the structure. Owing to the nature of the interaction problem, the contact force $F_{\text {ice }}(t)$ is not known a-priori as a function of time. Therefore, $F_{\text {ice }}(t)$ is postulated to be a function of relative velocity $v_{r}$ between the structure and ice sheet:

$F_{i c e}(t)=F_{i c e}\left[v_{r}(t)\right]$,

where $v_{r}(t)=\dot{u}(t)-v_{i c e}(t), \dot{u}$ and $v_{i c e}$ are respectively, the velocity of the structure and ice sheet.

The structure and the ice sheet are considered to be active dynamic systems. Hence, the solution of the problem entails a parallel treatment of both of them.

\subsection{Negative damping effect}

Based on the strain rate dependence ice failure characteristics, the theory of negative damping and self-excited vibration was proposed by Määttänen [16]. A mathematical model to describe negative damping and self-excited vibration was established through the combination of equation of motion and stress-dependent ice crushing strength.

The ice crushing strength is dependent on the loading rate, and the loading rate is dependent on the relative velocity between ice and structure. It is noticeable that the damping term on the left-hand side of the equation is dependent on the structure velocity $\dot{u}$, and the ice force is also dependent of structure velocity $u$. If the structure response-related part of the ice force could be extracted and moved to the left side of the equation, the damping coefficient will change, and the remaining ice loads will be ice velocity-related only.

This could be achieved by applying first order Taylor expansion at point $\dot{u}=0$, and the ice load can be modified as

$F_{\text {ice }}\left(v_{r}\right)=F_{\text {ice }}\left(v_{\text {ice }}-\dot{u}\right) \approx F\left(v_{\text {ice }}\right)+\frac{d F\left(v_{\text {ice }}\right)}{d v_{r}}(-\dot{u})$.

Then the Eq. (1) can be rewritten as

$M \ddot{u}+\left(C+\frac{d F\left(v_{i c e}\right)}{d v_{r}}\right) \dot{u}+K u=F\left(v_{i c e}\right)$.

If the term $d F\left(v_{i c e}\right) / d v_{r}$ attains a negative magnitude greater than the damping constant $C$, negative damping is achieved. Negative damping will lead to dynamic 
instability of system and growing fluctuation amplitudes. However, owing to the strong nonlinearity of ice force and damping, the amplitude does not increase indefinitely but is stabilized at a certain limit circle amplitude. This limit cycle marks that the energy dissipation in the system is balanced with the external energy supply in a vibration period, and it is a high-amplitude steady state.

\subsection{Model description}

The main object of the present study was to construct a model to exactly explain the problem of ice-induced vibrations. As a representation for the structure, a single degree of freedom oscillator is used. This is the simplest way of representing one mode of vibration of a structure, which is deemed sufficient to model the fundamentals of the interaction process. To reproduce the phenomenon of ice-induced vibrations with the model, the ice is portioned into $j$ independent ice elements, each modelled by a combination of springs $K_{i c e, j}$, which allows for elastic deformable, inelastic deformable, and local failure of the ice considering the failure length of ice crushing $C_{f}$, as shown in Fig. 4.

The ice failure process is controlled by the relative displacement and velocity between the ice sheet and the structure. To consider this, the near field is considered as a deformable part of ice sheet action on structure with a deformable length $\delta$, failure length $C_{f}$ and ice thickness $h$ as shown in Figs. 5(a) and 5(b) shows the model of the layered structure of the deformable part of ice sheet, and Eq. (2) is used to take into account the non-simultaneous contact phenomenon between the ice-structure.

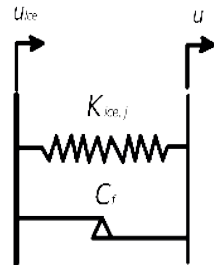

(a)

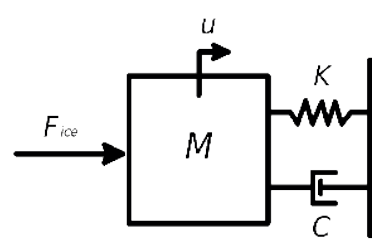

(b)
Fig. 4 Illustration of the analytical model. (a) Representation of a single ice element in the contact zone (b) The structure modelled as a singledegree-of-freedom oscillator

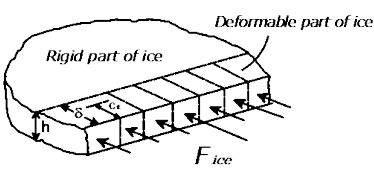

(a)

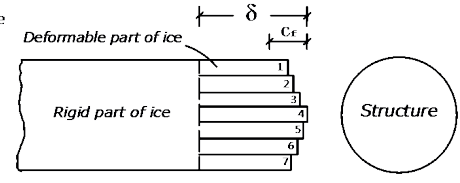

(b)
Fig. 5 Illustration of the analytical model of ice sheet. (a) Deformable part of ice sheet action on structure (b) Model of the layered structure of the deformable part of ice sheet

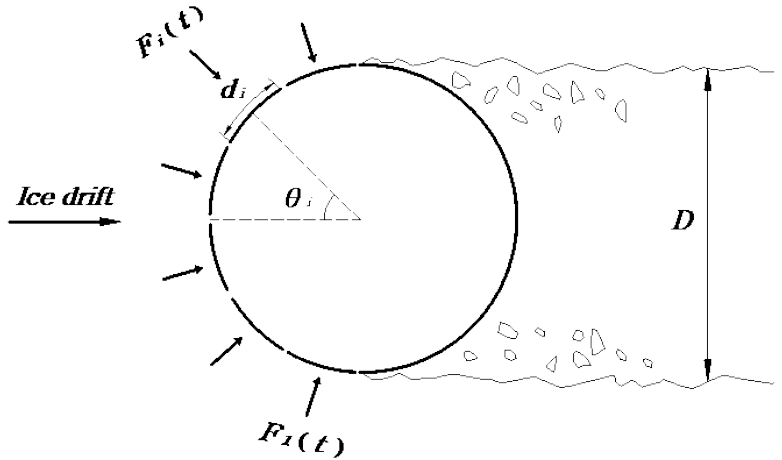

Fig. 6 Ice forces distribution on the rounded offshore structure

\subsection{Overall simulated approach procedure}

Response dependent loading on the structure is what separates the program from being an ordinary calculation of forced vibrations. The loading is response dependent because the contact force depends on the displacement in the ice and because the ice stress capacity is dependent on the relative velocity between ice and structure. Ice stress and deformation is calculated separately for each action point, in which the ice is represented by the elastic spring as shown in Fig. 6.

The crushing strength depends on stress rate, and the stress rate depends on the acting stress. At failure, the stress is equal to the crushing strength. To decide whether the ice fails or not in the current step, a predictor-corrector procedure is employed. The stress rate in the current step is calculated based on known stress in the last step. Crushing strength in the current step is then calculated from stress rate in the current step. The ice failure length is set to occur when radial ice stress is greater than ice crushing capacity; the ice will fail, and the displacement of ice should be reduced by failure length of ice crushing.

In the predictor step, the radial stress in the ice is calculated based on ice displacement $\delta^{X}$ of the previous step $X$ as Eq. (15):

$$
\sigma^{X}=\frac{K_{i c e} \delta^{X}}{r h \int_{0}^{\frac{\pi}{2}} \frac{1}{\cos ^{2} \theta+\mu \cos \theta \sin \theta} d \theta} .
$$

The force acting on the structure is calculated for each time step by integrating the stress over the polar angle and multiplying by two, accounting for the symmetry utilization as shown in Fig. 6. The harmonic terms only account for including the component of the radial normal stress and the tangential shear stress that is working in the ice drift direction as Eq. (16):

$F_{i c e}^{X}=2 h r \int_{0}^{\frac{\pi}{2}}\left(\sigma^{X} \cos \theta+\mu \sigma^{X} \sin \theta\right) d \theta$. 
In summary, the numerical method of ice-induced vibration provides a tool to predict the ice load and structural response when sea ice impacts a vertical offshore structure. The overall procedure of the simulating ice-induced vibration can be summarized as follows:

1. Determine ice velocity vice, ice failure length $C_{f}$, previous step time $t^{X}$, structural displacement $u^{X}$, structural velocity $\dot{u}^{X}$, and cumulative reduction of ice deformation $l^{X}$.

2. Calculate ice movement $u_{i c e}^{X}$, relative velocity $v_{r}^{X}$ and ice deformation $\delta^{X}=u_{i c e}^{X}-l^{X}-u^{X}$.

3. Calculate stress rate $\dot{\sigma}^{X}$ based on previous step stress according to Eq. (5).

4. Calculate ice crushing capacity $\sigma_{c}^{X}$ based on stress rate according to Eq. (6).

5. Calculate radial ice stress $\sigma^{X}$ according to Eq. (15).

6. Check if radial ice stress exceeds ice crushing capacity:

If $\sigma^{X}<\sigma_{c}^{X}$ go to (7).

If, $\sigma^{X} \geq \sigma_{c}^{X}$ set $l^{X}=u_{i c e}^{X}-u^{X}-\left(\delta^{X}-C_{f}\right)$ and recalculate $\delta^{X}=u_{i c e}^{X}-l^{X}-u^{X}$.

7. Calculate global force $F_{\text {ice }}$ according to Eq. (16). The global ice force is used to calculate the structural response in the next step.

\section{Results}

\subsection{Experiment validation}

During ice and structure interaction, studies have mainly focused on the ice loads and structure responses. The presented simulation parameters are determined from the tests described in Huang et al., and the mode of ice-structure interaction is frequency lock-in [30]. The test conditions of the structure and ice properties are listed in Table 1.

\subsubsection{Structure velocity}

During frequency lock-in, an approximately linear relation exists between the velocity amplitude of the structure and the ice sheet velocity. This relation was first found by Toyama et al. during model-scale experiments in the Saroma Lagoon [31] and were later confirmed in other experimental campaigns [30, 32-33]. Based on previous research work on ice-induced vibration, Karna and Turunen also found that the maximum amplitude of structure velocity is very close to the ice velocity vice during the self-excited vibration process, i.e., the ice force is influenced by the feedback effect of the structure [21]. The equation of correlation is expressed as Eq. (17):

$\dot{u}=\beta \times v_{\text {ice }}$,

where $\dot{u}$ denotes the maximum amplitude of structure velocity, $v_{\text {ice }}$ is the corresponding ice velocity and $\beta$ is a coefficient for the different experimental campaigns whose value range is approximately 1.0 to 1.5 [34].

According to test parameters of Huang et al., the structure stiffness of simulation process changed with three values. Figs. 7-9 show the correlation of maximum structural velocity against ice velocity during self-excited vibrations in different structural stiffness. The results also demonstrate that an almost linear relation exists between the maximum structural velocity and ice velocity during frequency lock-in. As is shown in Figs. 7-9, the frequency lock-in range in the test is from 80 to $255 \mathrm{~mm} / \mathrm{s}$, and from 70 to $230 \mathrm{~mm} / \mathrm{s}$ in the simulation. We can find that the range of ice velocity obtained by simulation is narrower than that measured by experiments during frequency lock-in. This discrepancy is most likely due to the difference between the experimental and the simulated ice crushing strengthstress rate curve. As the non-reproducibility is a characteristic of the ice force test, it is difficult to obtain an accurate ice crushing strength-stress rate curve.

Figs. 7-9 show the correlation of maximum structure velocity and ice velocity in different structure stiffness tests. The figures indicate that the maximum structure velocity is almost constant in low velocity interactions. When the ice velocity increases to $v_{1}$, the maximum structure velocity starts to exhibit almost linear growth. However, when the ice velocity increases to $v_{2}$, the maximum structure velocity starts to decrease and becomes lower than the ice velocity. As shown in Figs. 7-9, the computed maximum structure velocity shows that the ice

Table 1 Adopted from Huang et al. [30]

\begin{tabular}{|c|c|c|c|c|c|c|c|c|}
\hline \multirow[t]{2}{*}{ Test number } & \multirow{2}{*}{$\begin{array}{c}\text { Mode of } \\
\text { interaction }\end{array}$} & \multicolumn{2}{|c|}{ Ice conditions } & \multicolumn{5}{|c|}{ Model structure properties } \\
\hline & & $\begin{array}{l}\text { Ice velocity } \\
(\mathrm{m} / \mathrm{s})\end{array}$ & $\begin{array}{l}\text { Ice thickness } \\
\text { (m) }\end{array}$ & $\begin{array}{c}\text { Contact width } \\
\text { (m) }\end{array}$ & $\begin{array}{l}\text { Frequency } \\
\qquad(\mathrm{Hz})\end{array}$ & $\begin{array}{c}\text { Damping ratio } \\
(\%)\end{array}$ & $\begin{array}{l}\text { SDOF stiffness } \\
(\mathrm{kN} / \mathrm{m})\end{array}$ & $\begin{array}{c}\text { SDOF mass } \\
(\mathrm{kg})\end{array}$ \\
\hline 1 & FLI & 0.2 & 0.041 & 0.076 & 6.25 & 4.8 & 23.81 & 15.44 \\
\hline 2 & & 0.115 & 0.035 & & 4.29 & 4.9 & 27.44 & 37.77 \\
\hline 3 & & 0.08 & 0.035 & & 12.5 & 5.2 & 254.8 & 165.23 \\
\hline
\end{tabular}




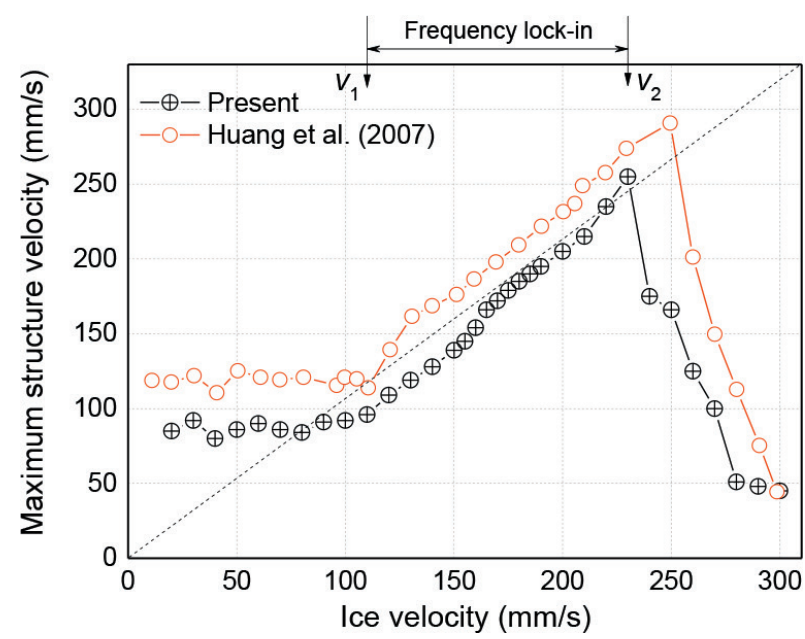

Fig. 7 Ice velocity $v_{s}$ the maximum structure velocity $(k=23.81 \mathrm{kN} / \mathrm{m})$

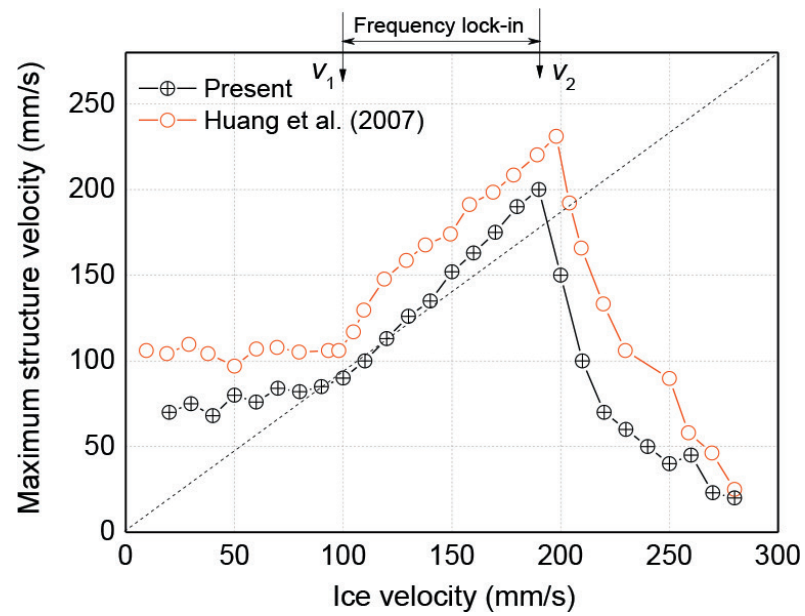

Fig. 8 Ice velocity $v_{s}$ the maximum structure velocity $(k=27.44 \mathrm{kN} / \mathrm{m})$

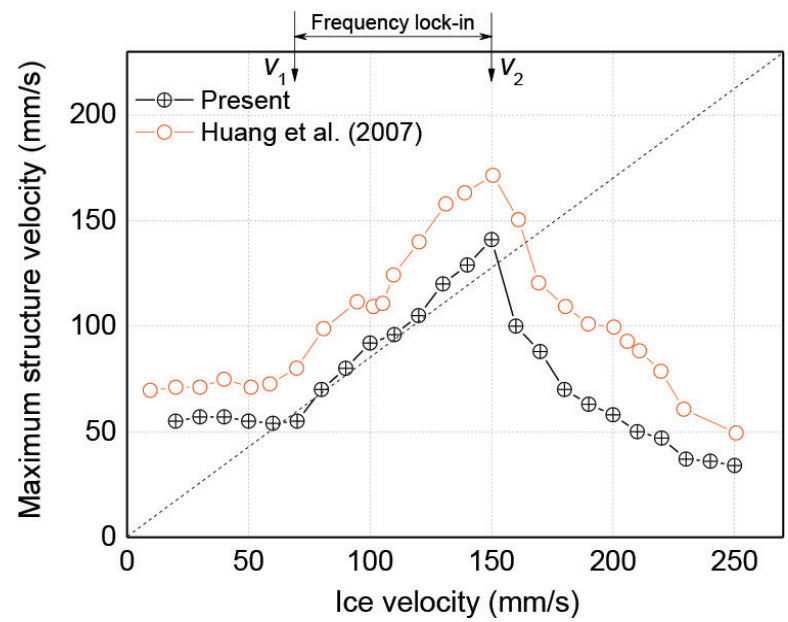

Fig. 9 Ice velocity $v_{s}$ the maximum structure velocity $(k=254.8 \mathrm{kN} / \mathrm{m})$

velocity range during frequency lock-in decreases with the increase of the structure stiffness. The phenomenon can also be confirmed from the experimental results obtained by Huang et al. [30]. They directly prove the validly of the proposed simulation method.

\subsubsection{Comparison of displacement response}

To analyse the ice and structure interaction process, the time domain results for structure displacement will be investigated in detail, and the response spectrum will be further discussed.

The simulation performance of the obtained structural displacement and displacement spectrum during frequency lock-in are shown in Figs. 10-12. The displacement spectrum was estimated after the mean value was subtracted. For highlighting the frequency range of interest, only the range of $2-20 \mathrm{~Hz}$ is displayed.

The computed displacement functions of the structure show good agreement with the test results of Huang et al. As shown in Fig. 10(a), when the ice velocity is $200 \mathrm{~mm} / \mathrm{s}$, the simulated mean value and standard deviation are 6.77 $\mathrm{mm}$ and $2.96 \mathrm{~mm}$, respectively, and the tested mean value and standard deviation are $6.81 \mathrm{~mm}$ and $2.47 \mathrm{~mm}$, respectively. The computed displacement response of the structure to two kinds of ice force parameters is shown in Figs. 11 and 12 . When the ice velocity is $115 \mathrm{~mm} / \mathrm{s}$, the simulated
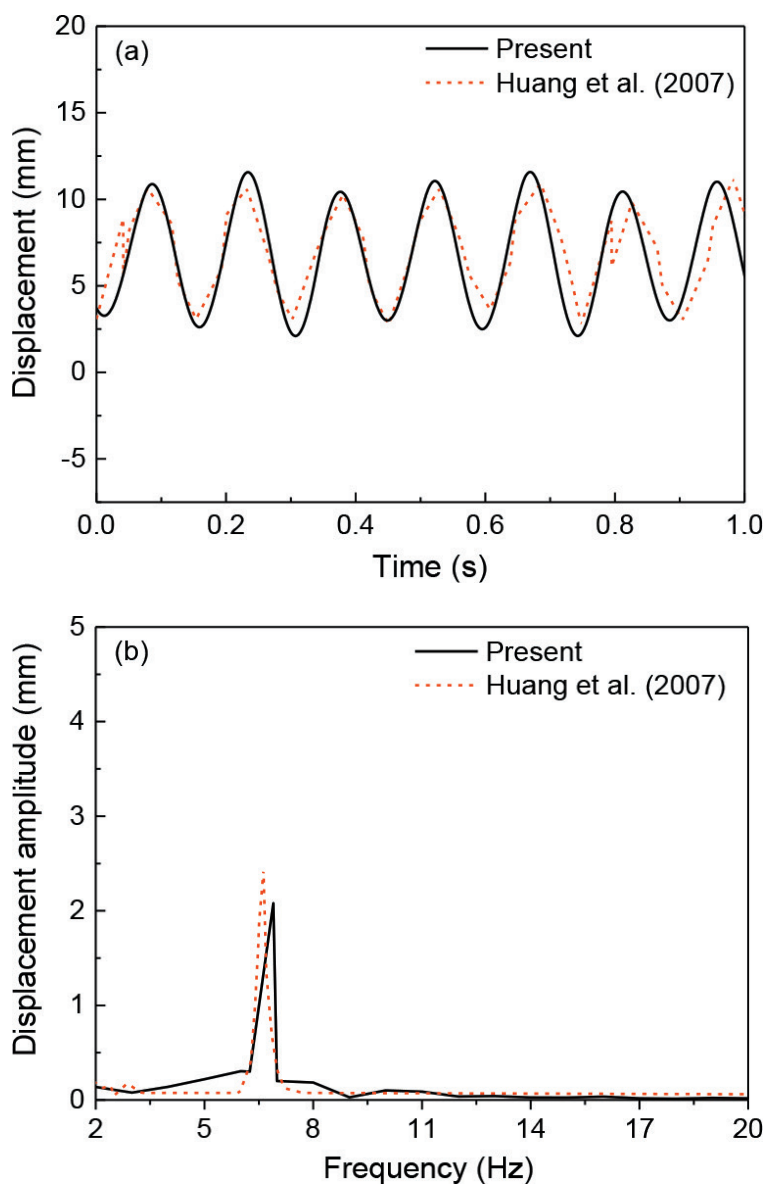

Fig. 10 Exhibition of simulation performance of test.1: (a) time history of displacement response of steady-state vibration; (b) frequency contents of time varying displacement response of steady-state vibration 

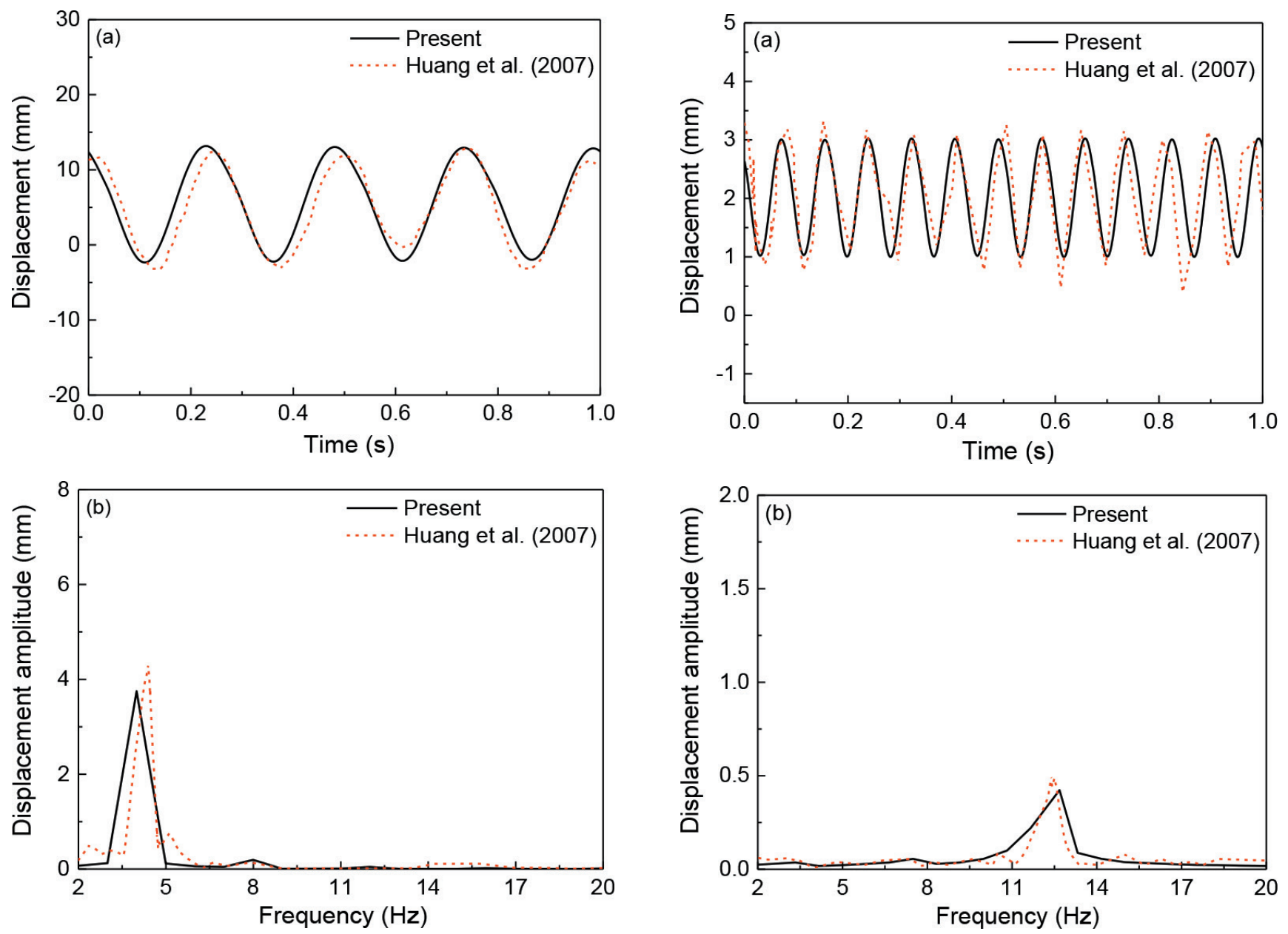

Fig. 11 Exhibition of simulation performance of test.2: (a) time history of displacement response of steady-state vibration; (b) frequency contents of time varying displacement response of steady-state vibration

mean value and standard deviation are $5.33 \mathrm{~mm}$ and 5.12 $\mathrm{mm}$, respectively, and the tested mean value and standard deviation are $4.89 \mathrm{~mm}$ and $4.89 \mathrm{~mm}$, respectively. When the ice velocity is $80 \mathrm{~mm} / \mathrm{s}$, the simulated mean value and standard deviation are $2.03 \mathrm{~mm}$ and $0.71 \mathrm{~mm}$, respectively, and the tested mean value and standard deviation are 2.01 $\mathrm{mm}$ and $0.81 \mathrm{~mm}$, respectively. The simulated approach showed a good agreement, and it provided results very similar to the actual test data.

Fig. 10(b) shows the displacement amplitude spectrum of one test sample and one numerical simulation result using the present approach, which shows a good fit. Obviously, the major frequency contents coincide well with the target. We also find that the simulated results show that the predominant structural response frequency is similar to the structural natural frequency. The frequency lock-in phenomenon is excited. This phenomenon may also be explained by the frequency lock-in phenomenon during self-excited vibrations.

Fig. 12 Exhibition of simulation performance of test.3: (a) time history of displacement response of steady-state vibration; (b) frequency contents of time varying displacement response of steady-state vibration

\subsubsection{Comparison of ice force}

The ice strength-stress rate curve and ice fracture length are coupled to model the internal fluctuating nature of ice loads. The simulation performance of the obtained ice forces and ice forces spectrum during frequency lock-in are shown in Figs. 13-15. The ice force spectrum was estimated after the mean value was subtracted. For highlighting the frequency range of interest, only the range of $2-20 \mathrm{~Hz}$ is displayed.

The computed ice forces functions show good agreement with the test results of Huang et al. As shown in Fig. 13(a), when ice velocity is $200 \mathrm{~mm} / \mathrm{s}$, the simulated maximum ice force is $241.37 \mathrm{~N}$, the mean value and standard deviation are $193.84 \mathrm{~N}$ and $41.21 \mathrm{~N}$, respectively, the tested maximum ice force is $267.08 \mathrm{~N}$, and the mean value and standard deviation are $172.12 \mathrm{~N}$ and $37.34 \mathrm{~N}$, respectively. As shown in Fig. 14 and Fig. 15, when ice velocity is 115 $\mathrm{mm} / \mathrm{s}$, the simulated maximum ice force, mean value and standard deviation are $193.98 \mathrm{~N}, 122.09 \mathrm{~N}$ and $36.87 \mathrm{~N}$, respectively; and the tested maximum ice force, mean value 

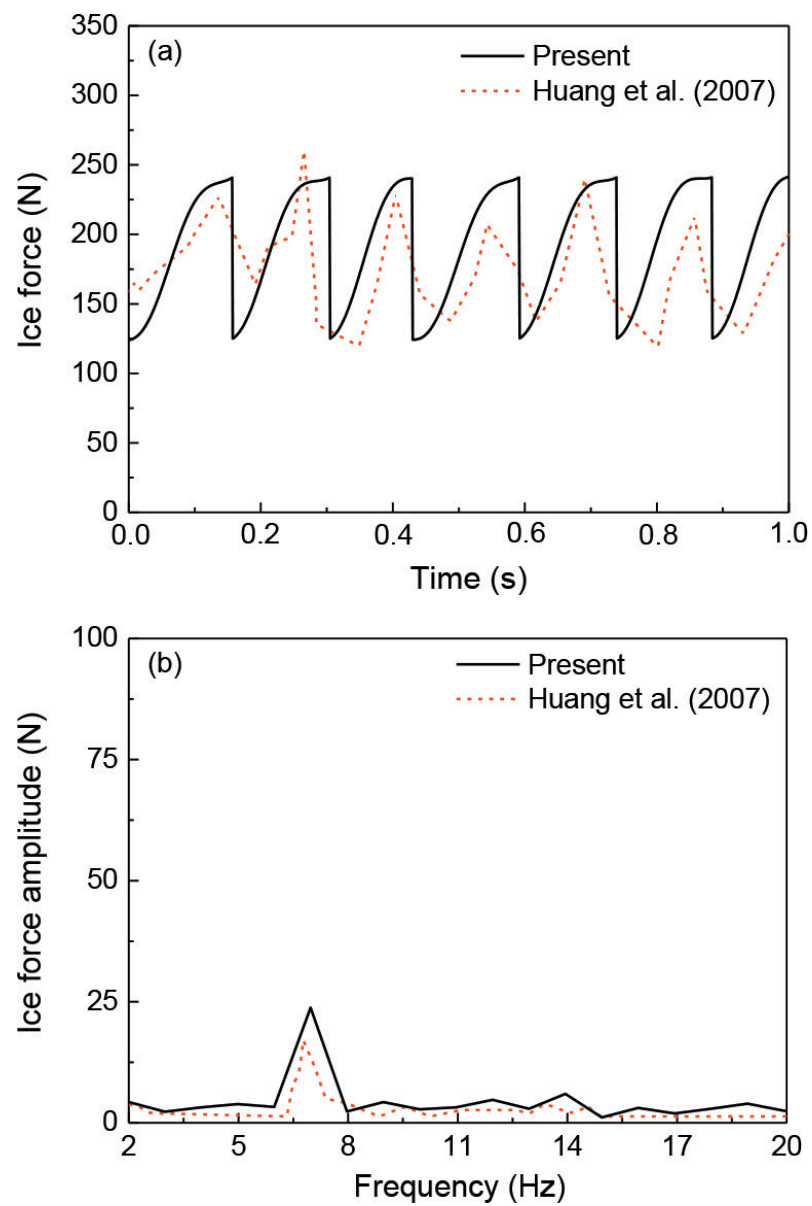

Fig. 13 Exhibition of simulation performance of test.1: (a) time history of ice force; (b) frequency contents of time varying ice force

and standard deviation are 200.6 N, $107.87 \mathrm{~N}$ and $42.37 \mathrm{~N}$, respectively. When the ice velocity is $80 \mathrm{~mm} / \mathrm{s}$, the simulated maximum ice force, mean value and standard deviation are $332 \mathrm{~N}, 252.8 \mathrm{~N}$ and $45.57 \mathrm{~N}$, respectively; and the tested maximum ice force, mean value and standard deviation are $335 \mathrm{~N}, 241.16 \mathrm{~N}$ and $43.77 \mathrm{~N}$, respectively. The simulated approach showed a good agreement, and it provided results very similar to the actual test data. This directly proves the validity of the simulation method.

Fig. 13(b) shows the ice forces amplitude spectrum of one test sample and one numerical simulation result using the present approach, which shows a good fit. Obviously, the major frequency contents of ice force coincide well with the target. We also find that the simulated results show that the predominant frequency of ice force is similar to the structural natural frequency. The frequency lock-in phenomenon is excited. This phenomenon may be can also be explained by the frequency lock-in phenomenon during self-excited vibrations. Ice force frequency lock-in is also a significant phenomenon during self-excited vibration process. The proposed simulation methodology-based negative
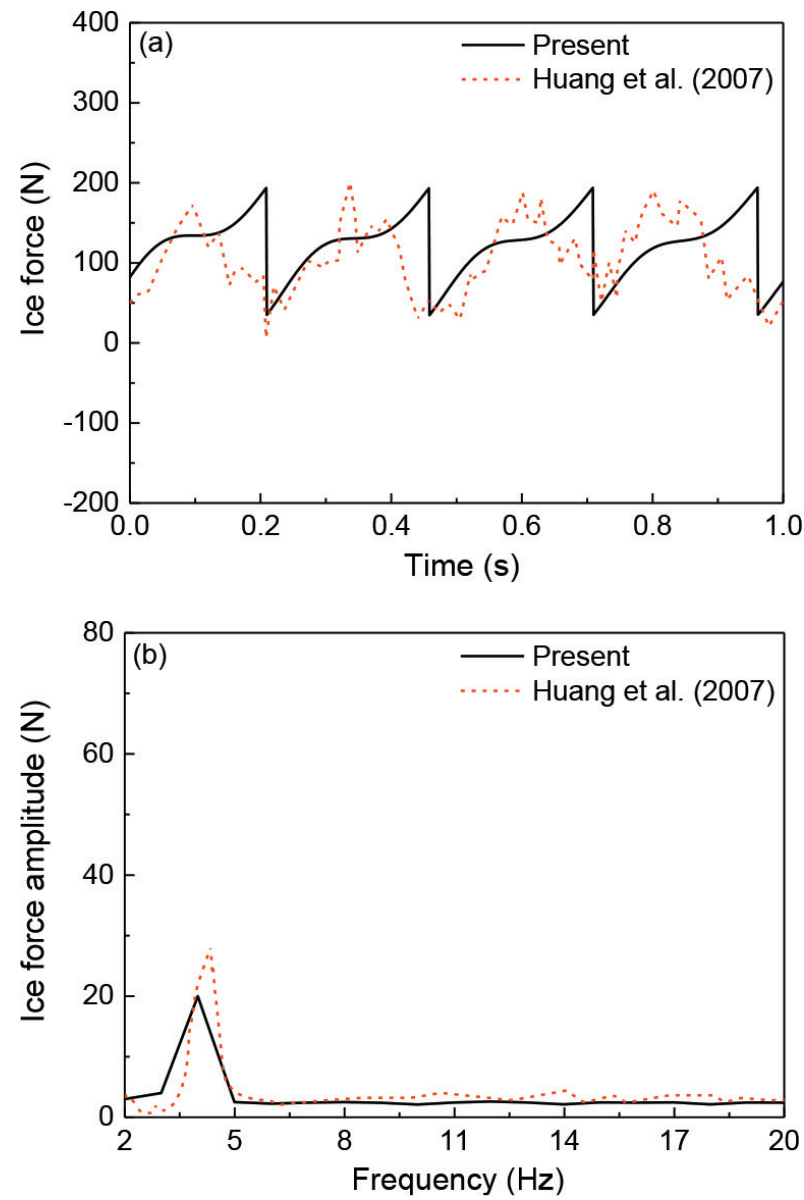

Fig. 14 Exhibition of simulation performance of test.2: (a) time history of ice force; (b) frequency contents of time varying ice force

damping effect is feasible. The results show a good agreement between the tested values in the laboratory and simulation values, which demonstrates the efficacy of the present simulation method.

\subsection{Full-scale measurement validation}

During ice and structure interaction, studies have mainly focused on the ice loads and structure responses. The presented simulation parameters are determined from full-scale measurements [35-36]. The modes of ice-structure interaction are intermittent brittle crushing in the full-scale measurement of Molikpaq and frequency lock-in in the full-scale measurement of Norströmsground lighthouse. The test parameters of the structure and ice properties are listed in Table 2.

Fig. 16 shows a typical simulation performance of ice force and acceleration for Molikpaq. As shown in Fig. 16(a), according to measured data, the maximum global ice force at Molikpaq is approximately 245.5 MN in the measurement period. According to the present model, the maximum value of the global ice force is $262.3 \mathrm{MN}$, which is close to the measured $245.5 \mathrm{MN}$. 
Table 2 Overview of ice-induced vibrations events parameters

\begin{tabular}{|c|c|c|c|c|c|c|c|c|}
\hline \multirow{2}{*}{$\begin{array}{l}\text { Ice-induced } \\
\text { vibrations } \\
\text { events }\end{array}$} & \multirow[b]{2}{*}{$\begin{array}{l}\text { Modes of } \\
\text { interaction }\end{array}$} & \multicolumn{2}{|c|}{ Ice conditions } & \multicolumn{5}{|c|}{ Structure properties } \\
\hline & & $\begin{array}{l}\text { Ice velocity } \\
(\mathrm{m} / \mathrm{s})\end{array}$ & $\begin{array}{l}\text { Ice thickness } \\
\text { (m) }\end{array}$ & $\begin{array}{l}\text { Contact width } \\
\text { (m) }\end{array}$ & $\begin{array}{l}\text { Frequency } \\
\quad(\mathrm{Hz})\end{array}$ & $\begin{array}{c}\text { Damping ratio } \\
(\%)\end{array}$ & $\begin{array}{c}\text { SDOF stiffness } \\
(\mathrm{GN} / \mathrm{m})\end{array}$ & $\begin{array}{l}\text { SDOF mass } \\
\text { (ton) }\end{array}$ \\
\hline Molikpaq & ICR & 0.01 & 2.4 & 80 & 1.26 & 20 & 10 & 160000 \\
\hline Norströmsgroud & FLI & 0.06 & 0.7 & 7.5 & 2.64 & 2 & 3.22 & 11700 \\
\hline
\end{tabular}
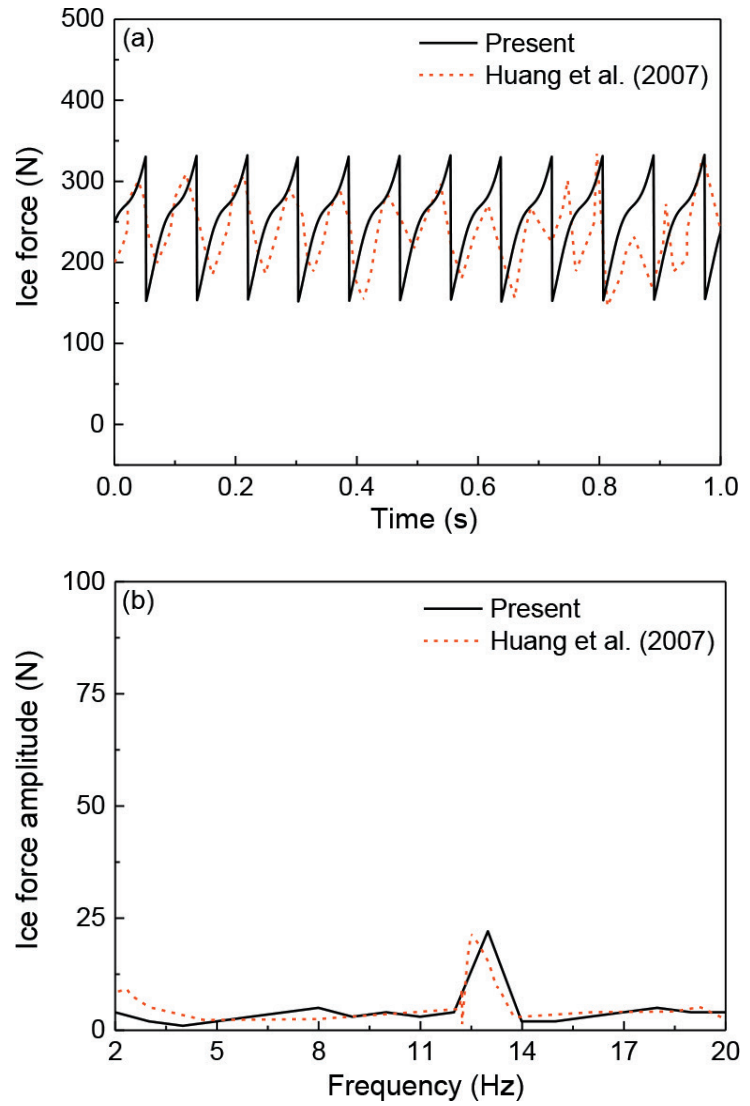

Fig. 15 Exhibition of simulation performance of test.3: (a) time history of ice force; (b) frequency contents of time varying ice force

As shown in Fig. 16(b), the simulated maximum acceleration is $-0.88 \mathrm{~m} / \mathrm{s}^{2}$, and the tested maximum acceleration is $0.71 \mathrm{~m} / \mathrm{s}^{2}$, respectively. The numerical model captures general features of the intermittent brittle crushing process. Obviously, the frequency contents of ice force coincide well with the target.

The simulated global ice force of Norströmsground lighthouse are plotted in Fig. 17(a). We can see that the simulated maximum value of the global ice force is approximately $1123.62 \mathrm{kN}$. According to measured data, the maximum global ice force at Norströmsground lighthouse is approximately $1054.44 \mathrm{kN}$ during the measurement period. The numerical model captures general features of the frequency lock-in process. As shown in Fig. 17(b), the simulated maximum acceleration is $-1.57 \mathrm{~m} / \mathrm{s}^{2}$, and the tested maximum acceleration is $-1.35 \mathrm{~m} / \mathrm{s}^{2}$, respectively.
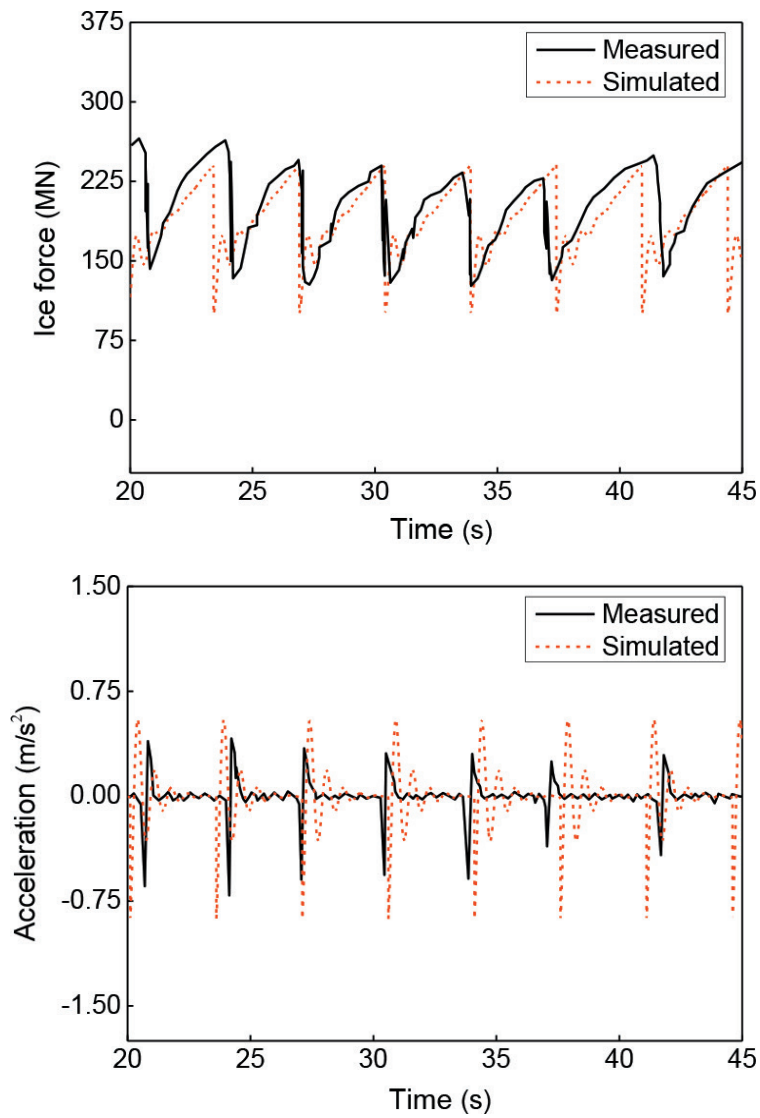

Fig. 16 Exhibition of the simulation performance for Molikpaq12 May 1986 (a) Simulated ice force vs measured ice force; (b) Simulated acceleration vs measured acceleration

The results show good agreement between the measured values in the field and simulation values, which demonstrate the efficacy of the numerical model again. The validity of the ice-induced vibration model is verified directly. In fact, we can see that the simulated results are higher than tested one, which reflect the conservative character of the simulation method. The simulation method is beneficial to practical engineering projects.

\section{Conclusions}

The focus of this research was to utilize a coupled model based on the ice strength-stress rate curve and ice fracture length for simulating ice-induced vibration. The simulation methodology is intended for an analysis of events in which the structure has vertical surfaces against the ice 

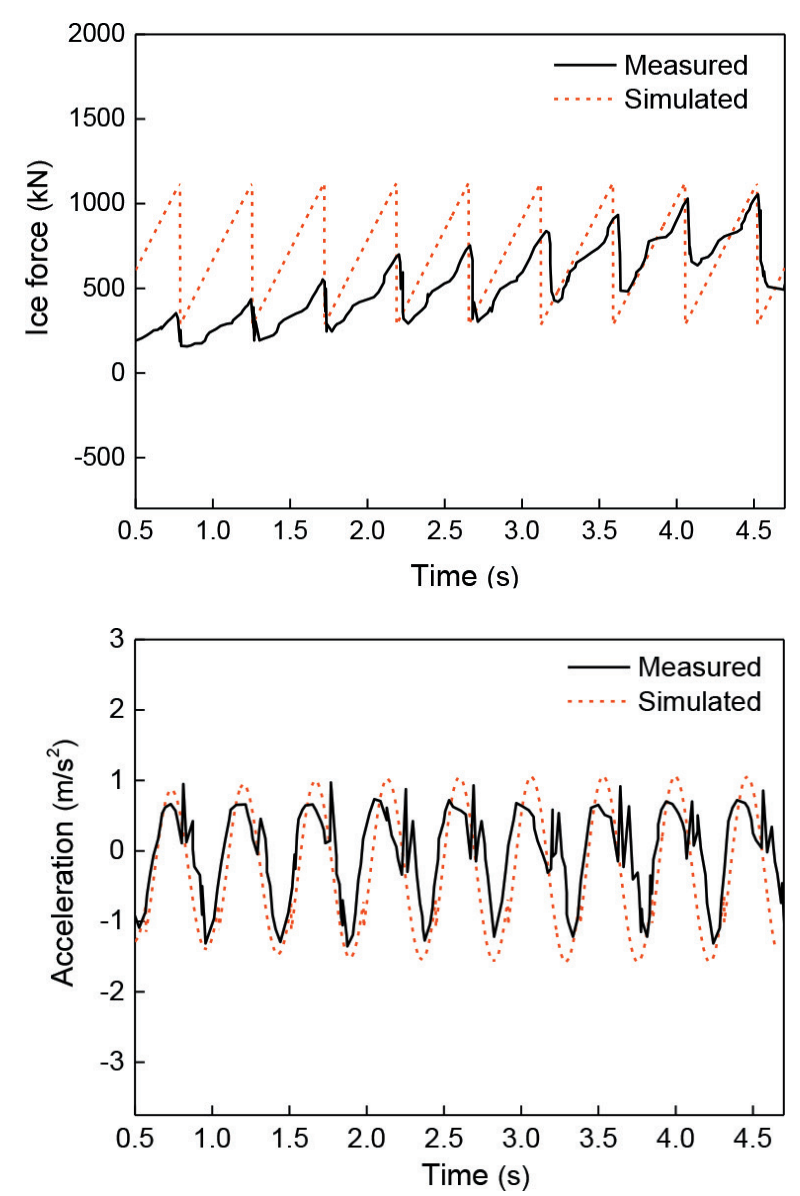

Fig. 17 Exhibition of the simulation performance for Norströmsground lighthouse 30 March 2003 (a) Simulated ice force vs measured ice force;

(b) Simulated acceleration vs measured acceleration

and in which there are forces resulting from drifting ice floes. It has been shown that the presented model is able to reproduce the process of ice-structure interaction for the model experiment and the full-scale structure.

\section{References}

[1] Yue, Q., Guo, F. "Physical Mechanism of Ice-Induced Self-Excited Vibration", Journal of Engineering Mechanics, 138(7), pp. 784-790, 2012.

https://doi.org/10.1061/(ASCE)EM.1943-7889.0000378

[2] Sodhi, D. S., Haehnel, R. B. "Crushing Ice Forces on Structures", Journal of Cold Regions Engineering, 17(4), pp. 153-170, 2003. https://doi.org/10.1061/(ASCE)0887-381X(2003)17:4(153)

[3] Timco, G. W., Johnston, M. "Ice loads on the caisson structures in the Canadian Beaufort Sea", Cold Regions Science and Technology, 38 (2-3), pp. 185-209, 2004.

https://doi.org/10.1016/j.coldregions.2003.10.007

[4] Sodhi, D. S. "Ice - Structure Interaction During Indentation Tests", In: Jones, S., Tillotson, J., McKenna, R. F., Jordaan, I. J. (eds.) IceStructure Interaction, International Union of Theoretical and Applied Mechanics, Springer, Berlin, Heidelberg, 1991, pp. 619-640. https://doi.org/10.1007/978-3-642-84100-2_31
During frequency lock-in, an approximately linear relation exists between the velocity amplitude of the structure and the ice sheet velocity. The simulated results demonstrate that an almost linear relation exists between the maximum structural velocity and ice velocity during frequency lock-in. According to the test parameters of Huang et al., the frequency lock-in process of the structure is simulated by using the present method. The computed displacement of structure and ice force functions shows good agreement with the test results of Huang et al. The results of generated sample functions show a good agreement between the test and simulation, and the major frequency contents coincide well with the target

Based on the full-scale measurements of the Molikpaq and the Norströmsground lighthouse, the ice force functions and acceleration of the structure are simulated using the present method. The maximum value of the ice forces process shows that the calculated is similar to that of the field measurement. The results of generated sample functions show good agreement between the field measurement and simulation. The numerical model can capture the general features of the interaction process: intermittent brittle crushing and frequency lock-in. It directly proves the validity of the simulation method. Consequently, the stochastic ice forces process of vertical offshore structure based on the present model can not only simulate global ice forces but can also be used in connection with FE programs to perform ice-induced vibration analysis.

\section{Acknowledgement}

This work was sponsored by the National Natural Science Foundation of China (51778108).

[5] Kama, T. "Mitigation of Steady-State Vibrations Induced by Ice", presented at The Fourth International Offshore and Polar Engineering Conference, Osaka, Japan, April 10-15, 1994.

[6] Hendrikse, H., Metrikine, A. "Interpretation and prediction of ice induced vibrations based on contact area variation", International Journal of Solids and Structures, 75-76, pp. 336-348, 2015. https://doi.org/10.1016/j.ijsolstr.2015.08.023

[7] Hossain, R., Taylor, R., Moro, L. "An assessment of sensitivity of the self-excited modelling approach for simulating dynamic ice-structure interactions to changes in temperature and scale effects", Ocean Engineering, 165, pp. 410-425, 2018. https://doi.org/10.1016/j.oceaneng.2018.07.029

[8] Nandan, H., Younan, A. H., Deng, L. "Ice induced vibration implementation of Määttänen model and development of design supplements", presented at Proceedings of the International Conference on Port and Ocean Engineering Under Arctic Conditions, Montreal, Canada, July 10-14, 2011. 
[9] Kärnä, T., Kamesaki, K., Tsukuda, H. "A numerical model for dynamic ice-structure interaction", Computers and structures, 72(45), pp. 645-658, 1999. https://doi.org/10.1016/S0045-7949(98)00337-X

[10] Withalm, M., Hoffmann, N. P. "Simulation of full-scale ice-structure-interaction by an extended Matlock-model", Cold Regions Science and Technology, 60(2), pp. 130-136, 2010. https://doi.org/10.1016/j.coldregions.2009.09.006

[11] Hendrikse, H., Ziemer, G., Owen, C. C. "Experimental validation of a model for prediction of dynamic ice-structure interaction", Cold Regions Science and Technology, 151, pp. 345-358, 2018. https://doi.org/10.1016/j.coldregions.2018.04.003

[12] Ji, X., Oterkus, E. "A dynamic ice-structure interaction model for ice-induced vibrations by using van der pol equation", Ocean Engineering, 128, pp. 147-152, 2016. https://doi.org/10.1016/j.oceaneng.2016.10.028

[13] Bjerkås, M., Skiple, A. "Occurrence of Continuous and Intermittent Crushing During Ice-Structure Interaction", In: 18th International Conference on Port and Ocean Engineering Under Arctic Conditions (POAC'05), Potsdam, New York, Unites States, 2005, pp. 1131-1140.

[14] Korzhavin, K. N. "Action of Ice on Engineering Structures", U.S. Army Cold Regions Research and Engineering Laboratory, Hanover, New Hampshire, United States, 1971.

[15] Timoshenko, S. P., Goodier, J, N. "Theory of elasticity", 2nd ed., McGraw-Hill Book Company, New York, NY, Unites States, 1951.

[16] Määttänen, M. "On conditions for the rise of self-excited ice-induced autonomous oscillations in slender marine pile structures", Winter Navigation Research Board, Helsinki, Finland, Rep. 25, 1978.

[17] Blenkarn, K. A. "Measurement and Analysis of Ice Forces on Cook Inlet Structures," presented at Offshore Technology Conference, Houston, Texas, United States, April 22-24, 1970. https://doi.org/10.4043/1261-MS

[18] Määttänen, M. "Numerical model for ice-induced vibration load lock-in and synchronization", In: Proceedings of the 14th International Symposium on Ice, Potsdam, New York, United States, 1998, pp. 923-930.

[19] Kärnä, T. "Finite ice failure depth in penetration of a vertical indentor into an ice edge", Annals of Glaciology, 19, pp. 114-120, 1994. https://doi.org/10.3189/1994AoG19-1-114-120

[20] Kärnä, T., Sippola, M. "Nonlinear loading phase in ice indentation", presented at The Sixth International Offshore and Polar Engineering Conference, Los Angeles, California, United States, May 26-31, 1996.

[21] Kärnä, T., Turunen, R. "Dynamic response of narrow structures to ice crushing", Cold Regions Science and Technology, 17(2), pp. 173-187, 1989. https://doi.org/10.1016/S0165-232X(89)80007-2

[22] Timco, G. W. "Indentation and Penetration of Edge-Loaded Freshwater Ice Sheets in the Brittle Range", Journal of Offshore Mechanics and Arctic Engineering, 109(3), pp. 287-294, 1987. https://doi.org/10.1115/1.3257022

[23] Eranti, E., Hayes, F. D., Määttänen, M., Soong, T. T. "Dynamic Ice-Structure Interaction Analysis for Narrow Vertical Structures", In: Proceedings of the 6th International Conference on Port and Ocean Engineering under Arctic Conditions, Quebec, Canada, 1981, pp. $472-479$.
[24] Ji, X., Oterkus, E. "Physical mechanism of ice/structure interaction", Journal of Glaciology, 64(244), pp. 197-207, 2018. https://doi.org/10.1017/jog.2018.5

[25] Sodhi, D. S., Morris, C. E. "Characteristic frequency of force variations in continuous crushing of sheet ice against rigid cylindrical structures", Cold Regions Science and Technology, 12(1), pp. 1-12, 1986. https://doi.org/10.1016/0165-232X(86)90015-7

[26] Sodhi, D. S. "Ice-induced vibrations of structures", In: Proceedings of the Ninth International Association of Hydraulic Engineering and Research Symposium on Ice, Sapporo, Japan, 1988, pp. 625-657.

[27] Jefferies, M. A. "Dynamic response of "Molikpaq" to ice-structure interaction", In: Proceedings of the 7th OMAE, Houston, Texas, United States, 1988, pp. 201-220.

[28] Jefferies, M. "Molikpaq dynamic ice-structure interaction at Amauligak 1985-6: measurements and data", presented at Ice Induced Vibrations JIP Workshop, Oslo, Norway, Nov. 29-30, 2010.

[29] Gagnon, R. E. "An explanation for the Molikpaq May 12, 1986 event", Cold Regions Science and Technology, 82, pp. 75-93, 2012. https://doi.org/10.1016/j.coldregions.2012.05.009

[30] Huang, Y., Shi, Q., Song, A. "Model test study of the interaction between ice and a compliant vertical narrow structure", Cold Regions Science and Technology, 49(2), pp. 151-160, 2007. https://doi.org/10.1016/j.coldregions.2007.01.004

[31] Toyama, Y., Sensu, T. "Model tests on ice-induced self-excited vibration of cylindrical structures", In: Proceedings of the 7th International Conference on Port and Ocean Engineering Under Arctic Conditions, Helsinki, Finland, 1983, pp. 834-844.

[32] Izumiyama, K., Uto, S. "Ice loading on a compliant indentor", In: Proceedings of the 16th international conference on offshore mechanics and arctic engineering, Yokohama, Japan, 1997, pp. 431-436.

[33] Timco, G. W, Irani, M. B., Tseng, J., Liu, L. K., Zheng, C. B. "Model tests of dynamic ice loading on the Chinese JZ-20-2 jacket platform", Canadian Journal of Civil Engineering, 19(5), pp. 819-832, 1992. https://doi.org/10.1139/192-093

[34] Hendrikse, H. "Ice-induced vibrations of vertically sided offshore structures", PhD Thesis, Delft University of Technology, 2017. [online] Available at: https://doi.org/10.4233/uuid:325ebcfb-f920400c-8ef6-21b2305b6920 [Accessed: 10.04.2019]

[35] Kärnä, T., Andersen, H., Gürtner, A. "Ice-induced vibrations of offshore structures - Looking beyond ISO 19906", presented at The 22nd International Conference on Port and Ocean Engineering Under Artic Conditions, Espoo, Finland, June 9-13, 2013.

[36] Bjerkås, M., Meese, A., Alsos, H. S. "Ice induced vibrations - Observations of a full scale lock-in event", In: The Twentythird International Offshore and Polar Engineering Conference, Anchorage, Alaska, United States, 2013, pp. 1272-1279. 